\title{
Technology and Learning Societies in the New Millennium (Indian Context): Content, Practice and Management
}

\author{
M.P.Thapliyal* and K.Subramnian** \\ *Department of Computer Science, Post Box 54, HNB Garhwal University, Srinagar (Garhwal, \\ PIN: 246174 Uttaranchal INDIA e-mail: mathuraprasad1 a)rediffinail.com \\ ** Deputy Director General (National Informatics Centre), IT Advisor to CAG of India 10 B.Z. \\ Marg, New Delhi-110 002 INDIA e-mail: ksdir@hub.nic.in
}

\begin{abstract}
The paper describes how Information Technology (with reference to Indian Context) can be harnessed for re- skilling and re-training of the existing work force to make them more productive and use the technology and creativity for better product design with reduced design life cycle. There are 10 new technologies i.e. Digital Subscriber line (DSL), Wireless Application Protocol (WAP), Extensive Markup Language (XML), Hyper Text Transfer Protocol (HTTP), Transmission Control Protocol /Internet Protocol (TCP/IP), Public Key Infrastructure (PKI), Fire Wall, Asynchronous Transfer Mode (ATM) Dense Wavelength Division Multiplexing and Open Source Operating System (Linux) that will be pushing Internet and Web enabled application. Taking the case of India, to become a software super power India has to develop professionals of international caliber for software development, content creation and services management. The new IT policy [11] enabled India to generate the necessary technical manpower for the development of software using the multi-sector resources. The Government made necessary facilitation for the private sector participation in creating the human resources, and to ensure quality of the human resources, there are appropriate quality assurance schemes positioned to inspect and monitor these institutions (private and public) and introduce standard assessment and evaluation systems for assuring quality education in the IT sector. These policies have worked well in terms of producing large amount of manpower to fulfil the requirements of the software industry. India has used the e-talented manpower availability as the economic advantage for positioning itself as software super power in the global scenario. All the multi-national companies have opted to open the software development centres, design centres and service centres in India to take cost advantage of skilled human manpower for their economic advantage. This has improved India's economic position in terms of monetary in-flow and export of goods and services.
\end{abstract}

The original version of this chapter was revised: The copyright line was incorrect. This has been corrected. The Erratum to this chapter is available at DOI: 10.1007/978-0-387-35609-9_29 
Key words: Fire Walls, HTTP,TCP/IP,WAP,XML,PKI,DSL, IT

\title{
1. INTRODUCTION
}

The technological development resulting in the global networking has brought access to information and knowledge [6] closer the common man $[3,13,14]$. The possibility of accessing various attributes of knowledge present and in the different parts of the world facilitates enhancement and transfer of skills with an unimaginable speed and accuracy. This has direct impact on the economic and social fabric of individual and the society. It is in this context that the educational systems of all countries should take cognisance of the emerging challenges, opportunities and threats. The process of acquiring knowledge [3] has undergone a tremendous change in recent past, with the global access to information. The quantum and quality knowledge avail able for access and transaction has greatly influenced human resource development and the economic activities of the society. The emergence of learning societies has no age, caste, community, economic in adequacies and other national barriers. Dissemination of knowledge and communication of the knowledge has brought the global network much closer. Reorganised distribution of wealth, redistribution of employment opportunities and skills, effective management of health systems, speedy communication through satellites, controlled traffic management and several other new features characterise the emergent life style, thanks to the explosion in the field of communication and information technology. The technology intervention has brought about significant changes in the learning styles.

\section{LEARNING SOCIETIES IN THE NEW MILLENNIUM: SOME UNIVERSAL DIRECTIONS}

\author{
New concepts such as "on demand education" for all and the \\ necessary \\ partnerships and alliances with private, public, Government and the
} community/institutions are outlined. There is a need for creation of professional certification agencies. The barriers of time, distance, universities and the nation will disappear by means of using Information Technology/products and services through multiple Medias to upgrade and uplift the human beings across the world. Special emphasis has been given for standardising Information Technology related curricula and also reforming the educational course contents in the Information Technology related subjects to make the graduates passing out of the institutions tobe 
immediately employable. The paper also describes how Information Technology can be harnessed for re-skilling and re-training of the existing work force to make them more productive and use the technology and creativity for better product design with reduced design life cycle.

The last mile problems faced in many of the developing countries can be reduced by means of introducing wireless technologies, which are becoming cheaper. The existing trained professional manpower which are available cheap in these developing countries to be retrained to use their talents in the content creation and developing specialised programming products such as development of language, protocol and drivers. The security technologies have to be introduced and the members of the organisations have to be informed in terms of the security policies and discharging functional responsibility by themselves instead of delegating the responsibility by their sub-ordinate staff. Though variety of technologies are available, the developing countries should appropriate weigh the requirements vis-à-vis cost and introduce appropriate technologies for selected applications, which demands security and better quality of service. The recommendation is to introduce costly technologies and provide services for those people who demand and afford to pay for it. The profit generated can be reused for making better infrastructure available and reduce the cost for others to use.

The developing economies have to operate by sharing resources and the concept of on-line communities has to be accepted as the better way of implementing the knowledge dissemination as well as economy of transition. The networking technologies are the ideal tool for introducing the concept of online communities to share, exchange, store products and tools and penetrate the global niche market.

The entertainment and media industry has to play a greater role in empowering the society. This requires self-regulated supportive media policies to be introduced for the developing nations where the desirability of information dissemination is an increasing necessity; but certain regulations in terms of value protection and preservation of culture, ethical and social values. The respective Governments should play regulatory as well as facilitating role for encouraging the media to have the specific contents of information to reach out to communities. However, certain regulatory policies are essential for media control and media management especially when it is exchanged across the nations. Certain national security requirements are to be kept in mind for exchange of media information across the nations. Cutting across tradition of national communities is the rise of "online communities", drawn together by politics, ethnicity, interests, gender, work or social cause. 
Developing nations [8] suffer many of the worlds most violent and infectious diseases, and have least access to information for combating them. Telemedicine and Health Net information service can bring critical knowledge to information poor hospitals and health workers. The potential is great, but only technology will not provide the solution. Interesting debates about the creation of necessary focused policies, infrastructure and human resource development, appropriate utilisation of the infrastructure to produce goods and services and become a market leader in the global scenario are taking place in various forums. Take for example where multi-media super corridor came up in Malaysia, the pace of content development to be used in the multi-media corridor is lagging in the implementation phase, thus, underutilisation of the costly infrastructure created.

Taking the case of India, to become a software super power India has to develop professionals of international caliber for software development, content creation and services management. The new IT [1,5] policy enabled India to generate the necessary technical manpower for the development of software using the multi-sector resources. The Government made necessary facilitation for the private sector participation in creating the human resources, and to ensure quality of the human resources, there are appropriate quality assurance schemes positioned to inspect and monitor these institutions (private and public) and introduce standard assessment and evaluation systems for assuring quality education in the IT sector. These policies have worked well in terms of producing large amount of manpower to fulfil the requirements of the software industry. India has used the etalented manpower availability as the economic advantage for positioning itself as software super power in the global scenario.

All the multi-national companies have opted to open the software development centres, design centres and service centres in India to take cost advantage of skilled human manpower for their economic advantage. This has improved India's economic position in terms of monetary in-flow and export of goods and services. Similarly, Korea took advantage of emanufacturing advantage and Singapore e-trade facilitation advantage. The Information Society Index [3,8], prepared by the World Times and the International Data Corporation, gives one way of measuring a country's preparedness, across four types of infrastructure.

a) Information: Creating the capacity to send and receive information by telephone, television, radio and fax.

b) Computer: Extending access to computers in schools, workplaces and homes, building networks and using software.

c) Internet: Expand the Internet in schools, workplaces and homes and enabling Electronic Commerce. 
d) Social: Building people's capacity to use information through education, freedom of the press and civil liberty.

\section{THINKING SCHOOLS AND LEARNING NATION}

A new paradigm Education aims to mould minds of tomorrow. Educated person is one who possesses values, the proper mindset, knowledge, skills, a responsive member of the family, a useful person in the society, and a good citizen of a good country. The new economy is built on technology; particularly fast advancing technologies like info-communications, the new revolutions in the life sciences. Speed, flexibility and nimbleness in seizing market opportunities will be critical. Marrying of entrepreneurial talents and technological expertise is crucial. So called knowledge based economy requires changes in the curriculum and the teaching strategies. Entails a change in the attitude and the mind-set of every member of the community the learners, educated, parents and the society at large. Science education should not only impart contents knowledge but also to develop inquiring mind and problem solving skills. Industry collaboration revolutionises teaching and learning experience.

The integrated community, where learning and collaboration among peoples, teachers, communities and private sector industry partnerships are tightly inter-woven. Thinking schools and Learning Nation is to be the paradigm of the new millennium. In the thinking schools and learning nation, concepts are based on desired outcomes of education such as values, skills, attributes to be accrued at different stages of education. These should provide right range of programs and activities that are to nurture the whole person-morally, physically, socially, intellectually and aesthetically. Involvement in community projects is essential and these are called "Heartware". The framework is a tripartite alliance between patents, schools and the community to achieve the desired outcomes. e-Learning has become a central feature of the new economy.

Technology [11] is rapidly forcing changes in the way business and economy are managed. The forces of globalisation and the technological advancements have redefined the nature of international competitiveness such that knowledge or intellectual capital is a new strategic asset for any individuals/companies and the nations. The success of businesses and economies hinge on how well they can leverage knowledge, skills, and creativity to create new wealth. Therefore, strong business and economies need a talented work force, which are keen to learn and re-learn, highly trained, flexible and adaptive to structural changes and quickly seize new opportunities. 
In this climate of permanent white water, the life cycles of products and hence knowledge skills are getting shortened. To stay as relevant and employable workers, they need to continuously upgrade and recharge their portfolio of skills and knowledge throughout their lives and to do so at an accelerated rate. There is no life long skills and life long employment. The new paradigm is "life long learning for life long employability". The businesses must also invest in their training and learning processes to speed up their innovation capacities and to explore new and superior business solutions to stay ahead of their competition. For example, Manpower-21 initiative of Singapore Government has the objective of building a nationwide learning capacity and life long learning as central strategy. The manpower 21 articulates the need to invest in the learning capacity of people primarily to take all new challenges of the new economy.

Job requirements change very rapidly. Public, private and people sectors work closely to develop school of life long learning, an integrated, comprehensive system to transform on the existing work force into globally competitive workers. New ways of learning. The Internet, which is a fast development open infrastructure, is deployed for education and has opened up new opportunities in learning. It offers companies a powerful tool to turbo charge their work-force learning efforts. It creates new "learning space" industry. e-Learning enables reinventing the way we learn things in our life. e-Learning is an appealing innovative concept for companies and learners.

New learning value proposition where the power of the responsibility of learning is given to the individual learners. In the past, organizations and trainers were the ones who took charge in providing learning opportunities and designing contents. With e-learning, [12] learners can receive customized training curricula according to his needs and his own time, pace and plays without compromising its effectiveness. Learning content can be granularlized into bite-sized modules that meets the learners' needs. Learner can also engage in collaborative learning and benefit from the experience and expertise of like-minded learners worldwide. This is impossible at the traditional set up except at an exorbitant cost. e-Learning offers plug-andplay training modularity, thus benefiting adult learners, enabling them effectively balances their work and family commitments while learning and enriching their skill sets. It enables learner access to knowledge information resources and services on a scale unimagined before. e-Learning hence makes learning "convenient, relevant and enjoyable". 


\section{E-ADVANTAGE FOR INDIA}

In the new millennium, e-learning has become essential to set affluent as a leading knowledge based environment in the global scenario. This requires co-operation at all levels i.e. political, social, economical, and community co-operative strategies have to be worked out for implementing e-learning to make the vast human resources available in India to make India global super power taking advantage of the huge human resource capital. Universal access and Government support and political will to implement a co-operative e-learning programme with the Government, industry and the people initiatives will make it possible the impossible, thus increasing the social status of India in the global map.

We have to use this strategy to become global human resource super power, capable of penetrating all sectors of economy and knowledge based human capital is e-advantage to India to acquire the global super power status. Model for India or for Nations aspiring to become Super Power in the new digital Economy. As a developing nation who wants to become super power in this digital age, a composite appropriate mix of American, Japanese and European model is the best solution to produce a strong socio-economic proposition. The workers should think quickly and produce quality goods and services with zero defects with enhanced productivity and the companies have to introduce incentive to perform by means of talents recognition, as talent is the key ingredient to success in the new digital economy.

\section{EDUCATION ON DEMAND - A CONCEPTUAL FRAMEWORK}

The computer communication and associated technologies are developing at a very fast rate and new demands are being made for providing entertainment, improving productivity of the work force, collaborative and co-operative efforts of many technology developers and service providers, the learning systems using friendly GUI interfaces and compulsions of social communications. In order to meet this demand, there is considerable investment made by many multi-nationals in the computers and communication sector to develop broad-band switches, the audio and video compression technologies, the high performance computing and creation of suitable information infrastructure to carry large volume of information consisting of text, voice and image. The components of such development concentrate on satellite communication technologies, signal processing techniques, development of digital video/HDTV/multi-media chips and fully digital communication using ISDN/ATM technologies for meeting the 
broadband communication [11] requirements. A vast country like India, having population nearly 100 crores needs to adopt various sophisticated modern technologies for alleviation of poverty and social upliftment by means of providing education to the masses. The distance-learning programme started few years ago under the umbrella of Indira Gandhi National Open University is trying to meet this demand. With the Government decision of implementing "literacy for all by the year 2010", we have to reach large population spread over all parts of India with the diverse environments, needs the adaptation of new educational courseware development and also change in delivery systems under the distance learning programme. The computerization and communication plan made for the Indira Gandhi National Open University to cover all the regional centers and study centers in India has to be connected through a high performance computer communication network and also require to initiate various steps for developing multi-media courseware to be disseminated through satellite transponders allocated for meeting the distance education demand. The education on demand can be developed with a vision of "TELETOPIA" (Telecommunications + Utopia) to provide a nationwide growth through Telecommunications [10]. The strategies are, a) Introduce Integrated Service of Telecommunications and Broadcasting [9], b) Promote the development of Multi-media Information \& Communication Technology, and c) Create living hood oriented society through Information \& Communication. The programme include Multi-media model city, pilot model project for next generation telecom technologies, next generation telecommunications R\&D project.

\section{CONCLUSION}

Development of online communities is essential and will introduce more competitive power cutting across politics, ethnicity, gender, and work/social cause.

Initiatives must be generated to have reverse knowledge flow from rural masses to the urban-elite and between developed and developing economies, thus enabling knowledge exchange for creating a sustainable development environment.

Developing economies of ASEAN region may adapt a balanced model comprising of : a) Just-in-time workers with necessary skills set with appropriate labour management. b) Talent recognition schemes should be evolved to enable the innovation of products and services that are packaged and marketed. c) Transformation of workers to knowledge workers in Enterprises and elevate them as Co-owners to improve productivity and 
implementation of appropriate change management is the priority. d) Just-intime marketing with flexibility and customization to meet the new demand of the consumers/markets.

Technology is neutral. Innovate with it ahead of competition is the challenge. Competitive issue is value creation. To generate income, new break-through in products and services to be launched. The "4 $\mathrm{Cs}$ " assume greater significance [C Computer, C -Communication, C-Content, and C Consumer Electronics].

Combination of Government regulation, industry self-regulation and consumer education is essential. A National Advisory Committee to work it out Industry code of practice.

e-Commerce code for personal information protection.

Parents advisory group for protecting children interest is recommended to be set up by every country in the region.

Global Internet requires global laws. There should be co-operation between various stages in ethical practices, rules and regulations governing e-Commerce, to work out uniform e-Laws within the region to transact the business within and out of the region. e-Revolution drives e-Laws to evolve to suit e-competitive nature of the economies and make the e-economies to grow across boundaries. Government must facilitate, promote and participate in "c (co-operative) - Commerce". Countries and collaborations which were built, anticipate, respond, adapt changes quickly will definitely succeed to become global power.

7 goals (connectivity, capacity, content, community, creativity, collaboration and cash) are to be achieved to transform nations to an Information Society. An Information Society Index is to be arrived at by measuring a country's preparedness across four types of infrastructure such as, information, computer, Internet and social.

Establishment of multilingual cyber kiosks is the only way in which information dissemination to the masses in the developing economies can take place.

A new framework "Heartware" of tripartite alliance between parents, schools and community to achieve the desired outcome, thus makes elearning a convenient and relevant. Re-transformation and re-generation of adaptation of new paradigm "Thinking Schools and Learning Nations" will be based on derived outcomes of education such as value, skills, attributes to be accrued at different stages of education and to provide right range of programs and activities that are to nurture the whole person - morally, ethically, socially, intellectually and aesthetically.

Enterprise should encourage creativity, talents recognition and innovation and accept knowledge workers, as co-owners such that balanced model of economy can be adapted to derive competitive advantage. 
Create suitable professional certification by reassessing the IT curriculum for meeting the growing industry demands with the desired skill sets.

Initiate appropriate steps for standardization of IT curricula within the nation/region and across the region.

Initiate suitable and appropriate policy, programs, projects to speedy creation of National Information Infrastructure, integrated to Regional Information Infrastructure and further integrated to Global Information Infrastructure to meet the learning demands, universal access, creating facility for life long learning, and adapting user-consumer centred learning technologies, development and deployment of new learning products, providing mass delivery technologies, collaborative and co-operative learning arrangements.

Technology is a facilitator, catalyst and a reforming agent. Preservation of social and cultural value of the system and the levelling of education opportunities to result in reducing the gap between Wealth and Poverty, Health and Misery, National Unity and Diversity.

Government to de-regulate education from a prime responsibility to a joint responsibility and work with commercial sector and community (NGOs) to provide learner/citizen driven education than an academia driven education.

The creation of National Digital Learning Laboratory and also setting up of National Warehouse for a digital multi-media courseware (Digital Courseware Warehouse) is a priority.

Select specialists and expedite digital multi-media content preparation for the region and initiate action plans to cover all subjects in a prioritized manner.

Professional certification efforts for engineering and professional education for increasing employability and integrating it as part of the curricula itself to reduce the gap between industry requirements vis-à-vis academic requirements, thus calling for a curriculum reassessment in the fast changing areas of information technology, management and communication.

Consortium/Partnership/Alliances approach for assessment, evaluation and credit sharing system between institutions has to be worked out. The partnership alliances have to facilitate a learning environment, extend support to learners as broker and co-ordinate the process and development of sharable digital multimedia courseware.

\section{REFERENCES}

1. Workshops and Conferences organized by Planning Commission held on 19th, 20th, $31^{\text {st }}$ May 2000 "Information Technology Action Plan", 1998199 report of the National Task Force on Information Technology and Software Development, Govt. of India. 
2. Balakrishnan N, ed., Emerging Communication Technologies and the Society, Indian National Science Academy, Narosa Publishing House, New Delhi, 1999.

3. Balasubramnian $\mathrm{G}$ "Designing a curriculum for knowledge society. "Experiment in Education. Vol.XXIXNo.7 October 2001.

4. Vidyasagar M., Reengineering the education system for a knowledge Society", Exec.VP Tata Consultancy Services, Hyderabad, India.

5. India as Knowledge Superpower : "Strategy for transformation," Task Force Report. Planning Commission, Govt. of India.

6. Barnett R (1996) "The Limits of Competence, knowledge", Higher Education and Society. Buckingham: SRHE and Open university Press.

7. Gascoigne E A. "Technology and Ethics", IEEE Asia-Pacific Channel, Feb.'96, p. 2

8. Janos B Cowie "Entering the Information Age: Implications for Developing Countries." IEEE Technology and Society Magazine. Dec. 1989, pp 21-24

9. Reinhart (1992) "Mobile Communications," IEEE Spectrum, vol. 29, no. 2, pp 27-29

10. Subramnian K (1997) "Telecommunications for Education and Development" In: Commonwealth Workshop, Malta

11. Subramanian K (2000) "IT as a Catalyst for Human Resource Re-Engineering for Knowledge Network Environments," India Eng. Congress New Delhi

12. Thapliyal M P (2000) "Network Technology To Support Teaching and Learning". Proceedings of $16^{\text {th }}$ World Computer Congress 2000 on Educational Uses of Information and Communication Technologies, Beijing (China), Aug. 21-25, 2000

13. Webster C W R and Smith C . (1995). "Information, Communication and New Technology in the Political Parties". Vol.3., Democracy and New Technology, pp. 1227 1235. Proceedings of the Contemporary Political Studies Annual Conference, University of York, 18th-20th April. Political Studies Association.

14. Webster F \& Robin, (1997), From ICTs to Information: Changing Conceptions of the Information Age", to be published in: Information, Communication and Society. 